\title{
Lung fibrosis-immunodeficiency-46,XX gonadal dysgenesis syndrome
}

INSERM

\section{Source}

INSERM. (1999). Orphanet: an online rare disease and orphan drug data base. Lung

fibrosis-immunodeficiency-46,XX gonadal dysgenesis syndrome. ORPHA:137631

Lung fibrosis-immunodeficiency-46,XX gonadal dysgenesis syndrome is characterised by immune deficiency, gonadal dysgenesis and fatal lung fibrosis. So far, it has been described in two sisters born to consanguineous parents. Both karyotypes were normal female $(46, X X)$. No genetic anomalies could be identified by comparative genome hybridization analysis of their genomes or by analysis of genes known to be associated with these types of anomalies. 